\title{
Colors and Imagery in Tailored Infographics for Communicating Health Information to Patients and Research Participants
}

\author{
Adriana Arcia, $\mathrm{PhD}, \mathrm{RN}^{*}$ \\ Columbia University School of Nursing
}

\begin{abstract}
Information visualizations, such as infographics, can be used to support comprehension of health information, but they must be well designed to be effective. Although a known best practice is to select colors and imagery that are culturally appropriate to the target audience, few specifics are offered in the literature, necessitating empirical studies. This article represents a synthesis across three studies to describe our lessons learned about the colors and imagery that supported comprehension of health information among urban Hispanic and African American adult research participants and patients in the Northeast, the majority of whom had low health literacy. Familiar palettes such as stoplight colors were effective for conveying value judgments. We saw a strong tendency toward strictly literal interpretation such that images were successful only if they were intended to be interpreted literally or if they were clearly meant to be metaphorical in nature. Images that included people were preferred over those that featured only objects. Patients strongly preferred imagery that reflected the subjective experience of their health condition over images that used abstract metaphors.
\end{abstract}

Keywords: Comprehension, audiovisual aids, information visualization, patient report outcomes.

Index Terms: H.1.2 a Human factors; I.6.9.c Information visualization J.3.b Health; K.m.d Healthcare

\section{INTRODUCTION}

Most people who need to make day-to-day decisions about their own health are not health experts. In fact, it is estimated that as few as $12 \%$ of adults in the United States have proficient health literacy, with even lower rates among racial and ethnic minorities [23]. Health literacy is often defined as the "capacity to obtain, process, and understand basic health information and services needed to make appropriate health decisions" [19]. There is an association between low health literacy and poor health outcomes that is thought to be mediated, in part, by inadequate comprehension of personal health information [21]. Therefore, strategies that can improve comprehension are worth exploring because they may yield health benefits. Information visualization has been proposed as one such strategy. However, visualizations vary in quality and in their appropriateness for an audience, to the point that poor designs can undermine comprehension $[11,17]$.

Although there is a growing body of literature dedicated to the attributes of effective visualizations, it is not clear to what extent that research addresses the needs of those who have limited health literacy. For example, among studies that evaluated different graphical formats to present patient-reported outcome data, few reported education or race/ethnicity, and of those that did, the samples were predominantly college educated and White [13], and thus not representative of the US population. Therefore, there is a

*adrianaxarcia@gmail.com

This work is licensed under a Creative Commons Attribution 4.0 International License. gap in the literature with respect to the attributes of information visualizations that will meet the needs of culturally, educationally, and racially diverse general audiences.

Much of the research on information visualization and comprehension has focused on comparing graphical formats [14], with less attention paid to other visualization attributes that can influence interpretation of meaning. Colors and imagery, in particular, must be culturally appropriate to convey the intended meaning effectively $[4,9,22]$. This presents a challenge to anyone wishing to communicate through visualization because the usercentered design processes necessary to empirically identify the colors and images that are appropriate for a specific audience are time- and resource-intensive [5]. Therefore, there is value to documenting what has worked well with specific audiences, in the hopes that these lessons can be reused. Additionally, it may be possible through research to identify some principles that can be applied more generally, such as with patients who have the same health condition but are demographically diverse. In this article we describe our lessons learned about the colors and imagery that supported comprehension of health information among urban Hispanic and African American adult research participants and patients in the Northeast.

\section{BACKground AND OBJeCtIVES}

The topic of colors and imagery that support comprehension became relevant to our research team during the Washington Heights/Inwood Informatics Infrastructure for CommunityCentered Comparative Effectiveness Research program (WICER, Study 1), a study to understand the health of a predominantly Hispanic northern Manhattan community [2]. We knew from our study data that many participants had low health literacy. Therefore, when we decided to return research data to the participants, as is advocated by the National Academy of Medicine [15], we decided to use visualizations tailored with individual data to do so. Our primary objective was to support comprehension of personal health information. Our secondary objective was to present the information in a way that was sufficiently engaging and personally meaningful as to motivate appropriate health selfmanagement (e.g., seeking help for depression symptoms).

We quickly found that the best practices documented in the health sciences literature answered very few of the questions we had about achieving our objectives with respect to our target audience. To fill this gap, we used a hybrid iterative participatory design process to develop tailored infographics that display the research variables we wished to return. Our hybrid process entailed the creation of many initial prototype designs by health and design experts followed by culling and refinement of those designs during participatory design sessions with members of our research cohort. A design was considered successful if it was among those preferred by design session participants and if their statements about its meaning matched our intended meaning.

We have subsequently used the same process twice more. In the New York City Hispanic dementia caregiver Research Program (NHiRP, Study 2), the audience was again made up of research participants, family caregivers of persons with dementia [3]. For 


\begin{tabular}{|c|c|c|c|}
\hline & Study 1 & Study 2 & Study 3 \\
\hline Name & $\begin{array}{l}\text { Washington Heights/Inwood } \\
\text { Informatics Infrastructure for } \\
\text { Community-Centered Comparative } \\
\text { Effectiveness Research (WICER) [2] }\end{array}$ & $\begin{array}{l}\text { New York City Hispanic dementia } \\
\text { caregiver Research Program (NHiRP) } \\
\text { [3] }\end{array}$ & $\begin{array}{l}\text { Asthma Control Infographics (ACI) } \\
\text { [1] }\end{array}$ \\
\hline Purpose of parent study & $\begin{array}{l}\text { To understand the health of a northern } \\
\text { Manhattan community }\end{array}$ & $\begin{array}{l}\text { To understand and support the needs of } \\
\text { Hispanic family caregivers of persons } \\
\text { with dementia }\end{array}$ & No parent study \\
\hline $\begin{array}{l}\text { Role of tailored } \\
\text { infographics }\end{array}$ & $\begin{array}{l}\text { Return individual- and cohort-level } \\
\text { research data to participants }\end{array}$ & $\begin{array}{l}\text { Return individual research data to } \\
\text { participants }\end{array}$ & $\begin{array}{l}\text { Support patient-provider } \\
\text { communication about clinical data }\end{array}$ \\
\hline $\begin{array}{l}\text { Infographic topics } \\
\text { (variables displayed) }\end{array}$ & $\begin{array}{l}\text { Self-reported: overall health, physical } \\
\text { activity, fruit and vegetable } \\
\text { consumption, chronic stress, fatigue, } \\
\text { depression and anxiety symptoms } \\
\text { Observed: blood pressure, body mass } \\
\text { index (BMI), waist circumference }\end{array}$ & $\begin{array}{l}\text { Self-reported: caregiving burden, overall } \\
\text { health, depression symptoms, } \\
\text { psychological distress, self-mastery, care } \\
\text { recipient's behavior and cognitive } \\
\text { functioning } \\
\text { Observed: care recipient's stage of } \\
\text { dementia }\end{array}$ & $\begin{array}{l}\text { Self-reported: asthma symptom } \\
\text { burden (used to calculate asthma } \\
\text { control score) } \\
\text { Observed: pulmonary function test } \\
\text { results }\end{array}$ \\
\hline Setting & New York City & New York City & New York City \& Philadelphia \\
\hline Design sessions & 5 English, 16 Spanish & 3 English, 3 Spanish & 4 English, 1 Spanish \\
\hline Participants & $\begin{array}{l}\text { Community members in Northern } \\
\text { Manhattan }(N=102)\end{array}$ & $\begin{array}{l}\text { Hispanic family caregivers of persons } \\
\text { with dementia }(N=16)\end{array}$ & $\begin{array}{l}\text { Adult patients with persistent asthma } \\
(N=21)\end{array}$ \\
\hline Mean age (range) & $53.2(19-91)$ & $61.8(49-86)$ & $50.2(31-73)$ \\
\hline Gender & 87 women, 15 men & 13 women, 3 men & 15 women, 6 men \\
\hline Ethnicity/Race & 95\% Hispanic & $100 \%$ Hispanic & $\begin{array}{l}38 \% \text { Hispanic } \\
62 \% \text { non-Hispanic Black }\end{array}$ \\
\hline $\begin{array}{l}\text { Marginal/inadequate } \\
\text { health literacy }\end{array}$ & $\begin{array}{l}\text { 53\% (Single Item Literacy Screener) } \\
\text { [6] }\end{array}$ & Not measured & $71 \%$ (Newest Vital Sign) [25] \\
\hline
\end{tabular}

Asthma Control Infographics (ACI, Study 3), the target audience was adult African American and Hispanic patients with persistent asthma and the purpose of the research was to develop tailored infographics that could serve as tools for patient-provider communication about medication adherence [1]. Key attributes of the studies and their participants are summarized in Table 1 . In this paper, I synthesize findings across these three studies to put forth the lessons our team has learned about the colors and imagery within visualizations that patients and research participants have found to be easily comprehensible and engaging.

\section{Related Work}

Evidence from a variety of experimental and qualitative studies indicates that colors and imagery can draw attention to and support comprehension of health information $[9,10]$. For example, parents who received medication administration instructions enhanced with pictograms or cartoons made fewer errors regarding pediatric medications than parents given only text instructions [12,26]. However, colors and images must be selected with care because the associated meanings vary by culture and the differences between those that are culturally appropriate and inappropriate can be subtle from an outsider's perspective [4,9,22]. For asthma care, the convention is to use stoplight colors (i.e., green, yellow/orange, red) to illustrate asthma action plans (summaries of patients' care plans) [16]. For low literacy audiences in particular, best practices are to use simple illustrations so as to minimize irrelevant and potentially distracting details and to link them closely with plainlanguage text $[9,14]$. Graphical elements should be familiar and relate to the referent in a familiar way [22]. For example, the design for an ATM symbol that showed a hand in a realistic position with respect to the cash was preferred over those with hands in unrealistic positions or without a hand at all [8]. Some concepts can be challenging to depict, such as "specialist" or increments of time
[10,24]. Metaphorical images that are action-oriented (e.g., stoplight, speedometer) may be preferable to those that imply a value judgment but not action [7].

\section{Methods}

This section provides a description of the general approach we used across the three studies, all of which were approved by the Columbia University Irving Medical Center institutional review board. Written informed consent was obtained from all participants.

\subsection{Participants}

Study 1 participants were adults who had participated in the parent study's community health survey. Similarly, Study 2 participants were recruited from among the Hispanic family caregivers of persons with dementia from the parent study. Study 3 participants were adults with persistent asthma recruited specifically for the visualization study from primary care clinics serving a population predominantly covered by Medicare/Medicaid in New York and Philadelphia. To be eligible, all participants had to be able to see and read large-print text in English or Spanish, per self-report. Given the importance of assessing comprehension, each participant attended only one session, to avoid learning effects.

\subsection{Development of Initial Prototype Designs}

For Study 1, the initial prototype designs (hereafter, 'designs') were developed by a large working group of health and biomedical informatics experts, a few of whom had design backgrounds. In Studies 2 and 3, a nurse scientist and a graphic designer collaborated on the initial designs in consultation with domain (e.g., dementia, asthma) experts. For each research variable or topic, we wished to visualize (e.g., asthma severity), we prepared multiple designs to represent a variety of design concepts. We used 
Table 2: Observations about the characteristics of successful and unsuccessful images

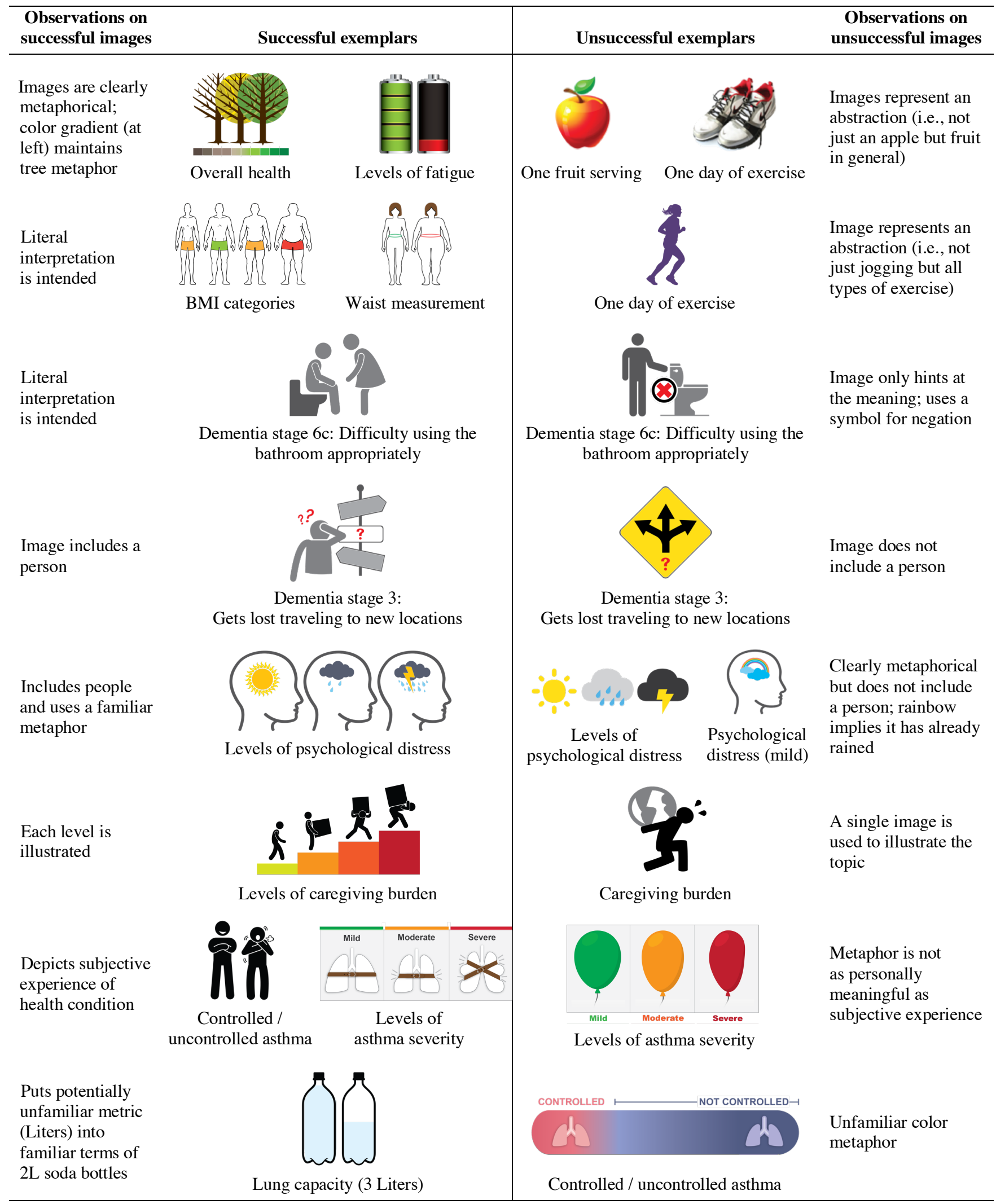


simulated data from fictitious people for tailoring the designs. Two bilingual members of the team translated content into Spanish.

\subsection{Iterative Participatory Design Sessions}

Participants were scheduled to design sessions by preferred language (English or Spanish). We measured health literacy in Study 1 [6] and Study 3 [25]. A set of designs was provided to each participant, printed in color, one to a page, on US Letter size card stock. Two members of the research team led participants in viewing and discussing the designs one at a time. Open-ended prompts such as "What information do you think we are trying to convey with this image?" were used to assess for comprehension. All the designs for a given variable/topic were compared head-tohead and put to a voice or hand vote in which participants selected the designs they preferred. The research team elicited suggestions for improvement and facilitated discussion about the elements of the designs that did and did not work, and why. If relevant to the topic, we asked participants if the design would motivate them to address the health issue depicted. Sessions lasted about two hours, for which time participants were compensated $\$ 50$.

\subsection{Analysis}

Research staff debriefed immediately after each session to discuss which designs received the most votes and were easily comprehended, which should be discontinued, and what modifications should be made to the designs that were retained. Refinements to the designs were made between sessions. Occasionally, entirely new designs were introduced based on participant feedback. We continued sessions until achieving design saturation, the point at which participants expressed satisfaction with the designs and suggested no further substantive changes. Detailed notes, transcripts, and audio-recordings of the sessions and debriefings were used to validate the design decisions and to serve as an audit trail. These artifacts also supported further analysis; we used an inductive approach informed by qualitative descriptive methodology to identify design attributes that contributed to appeal, comprehensibility, and motivational value. The full research team reviewed and affirmed the findings.

\section{FINDINGS}

In total, we showed 368 design iterations that yielded 19 pictograms of the stages of dementia and 29 tailorable infographics that participants deemed easily comprehensible and engaging. From the beginning, we were prepared to explore whether successful designs would vary by demographic characteristics such as level of literacy. Instead, we found in all three studies remarkable consensus among participants about the infographics they comprehended and preferred, lending consistency and credibility to our findings.

\subsection{Colors}

We tried out a variety of color palettes but found that none conveyed value judgements as clearly and powerfully as stoplight colors. We were concerned about potentially disadvantaging people with color blindness, but could not ignore how effective stoplight colors were at conveying the intended messages across a wide variety of health topics. We compensated by ensuring that all information encoded with color is also encoded with text.

Thus far, we have found two topics that are amenable to other color palettes. In both studies that had infographics for depression, participants preferred deepening shades of blue to indicate worsening symptoms (Figure 1). In study 2, participants responded favorably to an infographic for overall health in which a number line was illustrated with trees ranging from bare to lush; we used a brown-to-green gradient number line in this instance to maintain the metaphor (see Table 2). In the spirit of exploration, for Study 3 we tried a pink-to-purple gradient to signify the range from pink, healthy, well-oxygenated lung tissue to dusky, unhealthy, oxygendeprived tissue, as shown in Table 2 . This palette may yet be useful for clinicians trained in physical assessment, but we were not surprised that it was not particularly meaningful to patients.

\section{Ana's Depression Symptoms}

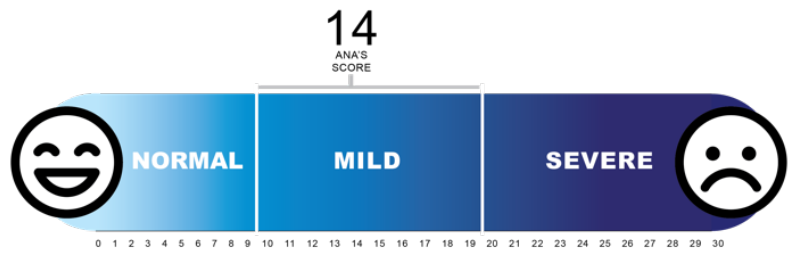

Figure 1: Deepening shades of blue were preferred over stoplight colors to convey the topic of depression symptoms. Reprinted from "Helping Hispanic family caregivers of persons with dementia "get the picture" about health status through tailored infographics," by A. Arcia, N. Suero-Tejeda, N. Spiegel-Gotsch, J. A. Luchsinger, M. Mittelman, \& S. Bakken, 2019, The Gerontologist, doi:10.1093/ geront/gnz085. CC Attribution-NonCommercial-NoDerivs license.

\section{Fruit Servings per Week}

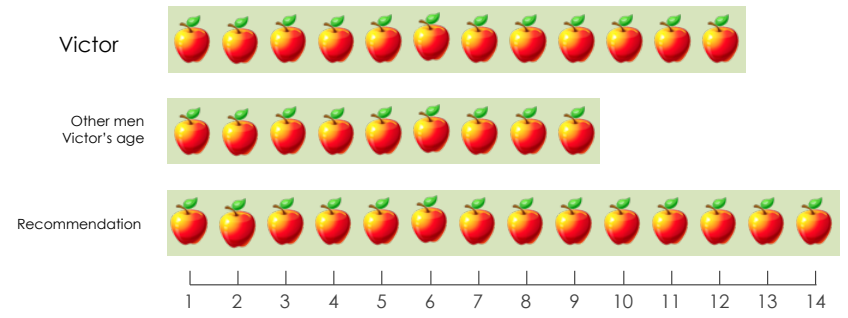

Figure 2: This iconographic bar chart was unsuccessful because most participants did not generalize beyond apples to other fruits.

\subsection{Imagery}

In Study 1, we attempted to use icons such as apples, carrots, and runners to represent fruit servings, vegetable servings, and days of with physical activity, respectively. These attempts were poorly comprehended because the icons were so often interpreted in a strictly literal fashion. For example, one design employed an iconographic bar chart to compare "Victor's" fruit servings per week to that of other men his age and to the nutrition recommendation (Figure 2). Participants' comments centered on apples ("so many apples!") to the exclusion of any other types of fruit. Only rarely would a participant draw attention to the title and a) suggest that the apples represented fruit generally, and b) the recommendation only worked out two servings per day. Our attempt to show a variety of fruits, as participants suggested, were unsuccessful as subsequent groups assumed that Victor was eating the same set of fruits every time, including an entire pineapple. It became clear that the graphical convention of using icons to represent multiple instances of a slightly abstract category (fruits, vegetables, exercise) was unfamiliar for this audience. Ultimately, we were unable to find imagery that would serve this purpose and resorted to unadorned bar charts instead. Other concepts that proved difficult to visualize were negation (e.g., the absence of something) and units of time (e.g. days). We adapted to the former 


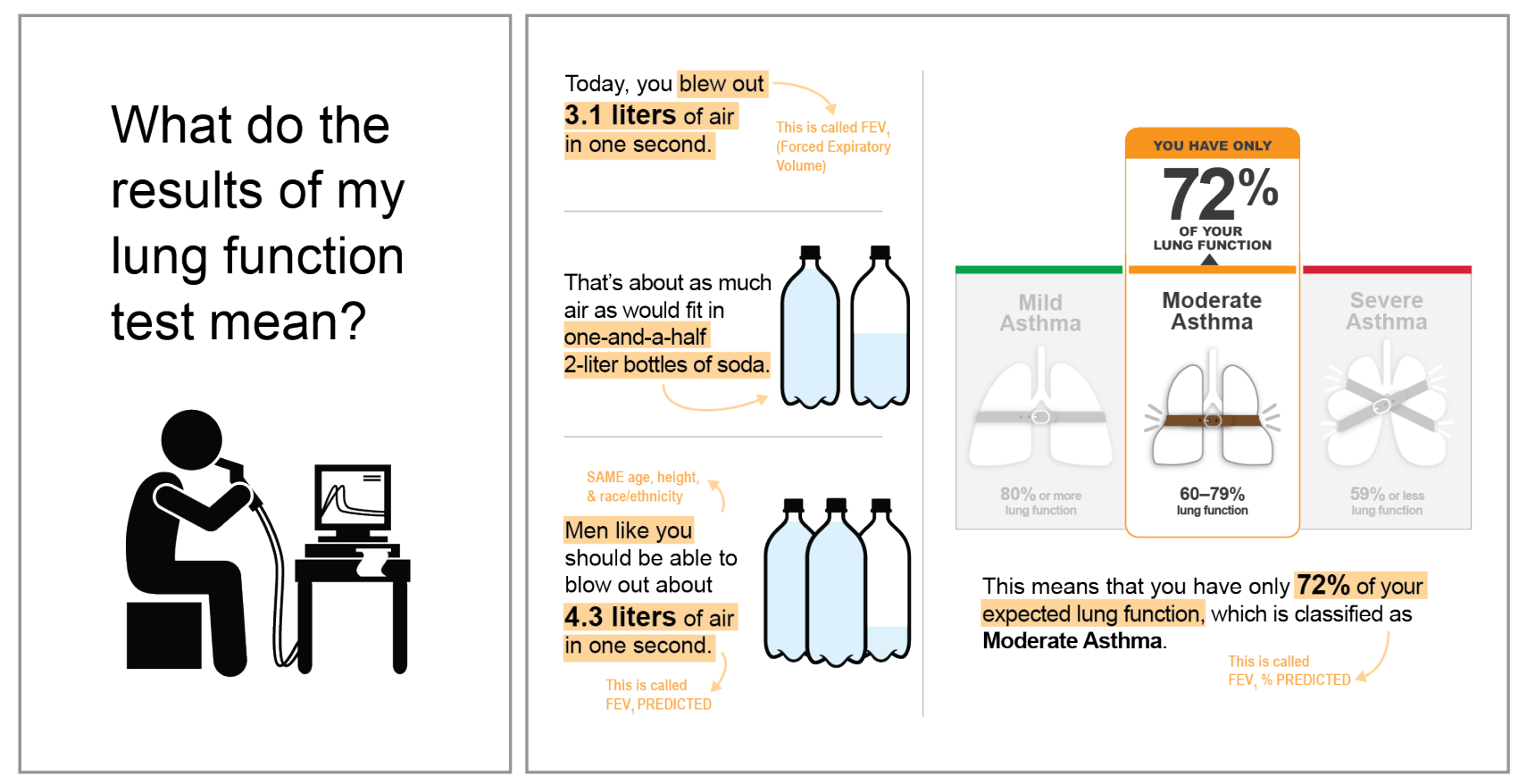

Figure 3: The front cover $(L)$ and inside of a pamphlet $(R)$ showing results of a lung function test.

CC BY 4.0 Adriana Arcia \& Nicole Spiegel-Gotsch for Columbia Nursing, https://doi.org/10.7916/d8-w8hz-w605, p. 4.

by showing the presence of something (e.g., a frown instead of the absence of a smile) and to the latter by relying on text. As another example of literal interpretation, for an infographic about psychological distress, we heeded the advice of a participant to use the image of a head with a sun inside instead of a rainbow (see Table 2) because the rainbow implies that it has already rained -a level of nuance we did not intend.

The images that were readily comprehended were ones that were intended to be interpreted literally, or were obviously intended to be metaphorical as shown in the multiple examples in Table 2. In general, participants responded very well to the use of familiar metaphors. However, of the images we tried out to convey asthma severity, participants strongly preferred those that reflected the subjective experience of the disease (e.g., belted lungs, inspired by the Dalhousie Dyspnea Scales [18]) over the more abstract metaphors (e.g., balloons). The images of the 2-liter soda bottles in Figure 3 got a very enthusiastic reception because they helped viewers unaccustomed to using liters translate the metric into more familiar terms. One participant even commented that the bottle image would stay with him "forever."

We observed a general preference for images that included people (e.g., lost person) over those that featured objects (e.g., road sign). Participants favored number lines with illustrations anchoring the endpoints (Figure 1) or each category (see caregiving burden in Table 2) over those that had no illustrations or only a single illustration to convey to topic of the infographic. Happy and sad faces were effective for conveying value judgments.

\section{Discussion}

This synthesis highlights the colors and imagery that helped make health-related visualizations easily comprehensible and engaging for urban Hispanic and African American adult research participants and patients, an audience whose visualization needs are understudied. Our findings are important because they shed light on how to meet the visualization needs of people with limited health literacy. Implementation of these findings and further research with similar populations can help insure that they are not left behind as the field of visualization continues to innovate.
Our findings about literal interpretation are consistent with prior evidence that low-literacy audiences in particular often attend to irrelevant details in images [9]; it stands to reason that those details would be important if a literal interpretation were warranted. As in previous studies [10,24], we were stymied in our attempts to visualize units of time, negation/absence, and low-level abstractions like fruit or physical activity. Similarly to Foster and Afzalnia, whose participants preferred ATM symbols that incorporated a hand over those that showed only cash [8], our participants preferred imagery that included people.

For asthma-specific information, patients favored imagery that reflected their subjective disease experience. Would the same be true of other health conditions? For example, if patients suffer from fatigue, will they prefer the battery metaphor, a depiction of a tired person, or something else altogether? Images of 2-liter soda bottles helped to translate an unfamiliar metric for air volume into familiar terms. It is worth exploring how this technique can be applied to explicating other metrics that patients encounter in the course of their care. There is much to be learned about the imagery that will be most resonant for specific health conditions.

The value of these findings is that they demonstrate an application to urban Hispanic and African American adults of the guidance that imagery be selected for its cultural appropriateness. Further study is needed to explore if these findings apply to other demographic groups, levels of literacy or education, geographic regions, or health conditions. It is possible that our participants' preferences reflect those of US culture at large rather than those of specific geographic or racial/ethnic groups. Would findings be similar for groups with substantially higher levels of literacy?

\subsection{Limitations and Future Directions}

Our studies have some limitations inherent to the study design, including the possibility of learning effects and statements about health behavior intentions potentially motivated by social desirability bias. We also expect that seeing one's own data could be a very different experience from seeing simulated data, as was used in these studies. For these reasons we are a) currently refining a rigorous method of individual comprehension testing that is 
appropriate for this audience, and b) planning a clinical trial to evaluate the impact of tailored infographics on pediatric asthma medication adherence. We hope to learn more about what happens to comprehension when people are presented with information about themselves that is unflattering or unfavorable. Some research suggests that unfavorable information is poorly received only when it is unexpected [20].

We have focused primarily on the needs of individuals with low health literacy, representing the majority of our participants. However, participants who did have higher literacy or education did not stand out as having different needs or preferences than the larger group. Further study is needed to understand precisely how visualization needs do or do not differ across levels of literacy or domain expertise. Perhaps it is possible to ease comprehension effort, even for expert audiences, through the application of these lessons learned.

\section{ConClusion}

Participatory design methods require a greater resource investment than reliance only on expert opinion. However, we have found extraordinary value in working directly with members of our target audience and advocate that visualization projects should have participatory design components. Further testing and application of our findings may eventually help to streamline design processes by reducing the range of unknowns to be explored. We have touched on only a handful of health topics, leaving open many avenues worthy of exploration.

\section{ACKNOWLEDGMENTS}

The author thanks Suzanne Bakken, Niurka Suero-Tejeda, Nicole Spiegel-Gotsch, and Maureen George. This work was supported in part by the Agency for Healthcare Research and Quality (R01 HS019853, R01HS022961), New York State Department of Economic Development NYSTAR (C090157), the National Institute of Nursing Research (T32NR007969, R01NR01443003S1) and the Columbia University School of Nursing Intramural Pilot Grant Program.

\section{References}

[1] A. Arcia, M. George, M. Lor, S. Mangal, and J.-M. Bruzzese, "Design and comprehension testing of tailored asthma control infographics for adults with persistent asthma," Applied Clinical Informatics, in press.

[2] A. Arcia, N. Suero-Tejeda, M. E. Bales, J. A. Merrill, S. Yoon, J. Woollen, and S. Bakken, "Sometimes more is more: iterative participatory design of infographics for engagement of community members with varying levels of health literacy.," JAMIA, vol. 23, no. 1, pp. 174-183, Jan. 2016.

[3] A. Arcia, N. Suero-Tejeda, N. Spiegel-Gotsch, J. A. Luchsinger, M. Mittelman, and S. Bakken, "Helping Hispanic family caregivers of persons with dementia 'get the picture' about health status through tailored infographics," The Gerontologist, in press.

[4] M. M. Aslam, "Are you selling the right colour? A cross-cultural review of colour as a marketing cue," Journal of Marketing Communications, vol. 12, no. 1, pp. 15-30, Mar. 2006.

[5] P. A. Barclay and C. A. Bowers, "Design for the Illiterate: A Scoping Review of Tools for Improving the Health Literacy of Electronic Health Resources," presented at the Proceedings of the Human Factors and Ergonomics Society Annual Meeting, 2017, vol. 61, pp. 545-549.

[6] L. D. Chew, J. M. Griffin, M. R. Partin, S. Noorbaloochi, J. P. Grill, A. Snyder, K. A. Bradley, S. M. Nugent, A. D. Baines, and M. Vanryn, "Validation of screening questions for limited health literacy in a large VA outpatient population.," Journal of General Internal Medicine, vol. 23, no. 5, pp. 561-566, May 2008.

[7] P. M. Desai, M. E. Levine, D. J. Albers, and L. Mamykina, "Pictures worth a thousand words: Reflections on visualizing personal blood glucose forecasts for individuals with Type 2 diabetes," in Proceedings of the 2018 CHI Conference on Human Factors in
Computing Systems, New York, New York, USA, 2018, pp. 1-13.

[8] J. J. Foster and M. R. Afzalnia, "International assessment of judged symbol comprehensibility," International Journal of Psychology, vol. 40, no. 3, pp. 169-175, 2005.

[9] P. S. Houts, C. C. Doak, L. G. Doak, and M. J. Loscalzo, "The role of pictures in improving health communication: a review of research on attention, comprehension, recall, and adherence.," Patient Education \& Counseling, vol. 61, no. 2, pp. 173-190, May 2006.

[10] M. G. Katz, S. Kripalani, and B. D. Weiss, "Use of pictorial aids in medication instructions: a review of the literature.," American Journal of Health-System Pharmacy, vol. 63, pp. 2391-2397, Dec. 2006.

[11] A. Lazard and M. Mackert, "User evaluations of design complexity: the impact of visual perceptions for effective online health communication.," International Journal of Medical Informatics, vol. 83 , no. 10, pp. 726-735, Oct. 2014.

[12] M. Leiner, J. Peinado, A. Baylon, I. Lopez, and I. Pathak, "Divide and conquer: improving parental understanding of health-related instructions using sequential pictorial instructions.," Health Education Research, vol. 33, no. 2, pp. 104-113, Apr. 2018.

[13] M. Lor, T. A. Koleck, and S. Bakken, "Information visualizations of symptom information for patients and providers: a systematic review.,"JAMIA, vol. 26, no. 2, pp. 162-171, Dec. 2018.

[14] L. Meloncon and E. Warner, "Data visualizations: A literature review and opportunities for technical and professional communication," in 2017 IEEE International Professional Communication Conference (ProComm), pp. 1-9, 2017.

[15] National Academies of Sciences, Engineering, and Medicine, Health and Medicine Division, Returning individual research results to participants: guidance for a new research paradigm. Washington (DC): National Academies Press (US), 2018.

[16] National Asthma Education and Prevention Program, "Expert Panel Report 3 (EPR-3): Guidelines for the Diagnosis and Management of Asthma-Summary Report 2007.," Journal of Allergy and Clinical Immunology, vol. 120, no. 5 Suppl, pp. S94-138, Nov. 2007.

[17] D. T. Nystrom, H. Singh, J. Baldwin, D. F. Sittig, and T. D. Giardina, "Methods for patient-centered interface design of test result display in online portals," EGEMs (Generating Evidence \& Methods to improve patient outcomes), vol. 6 , no. 1, p. 15, 2018 .

[18] P. Pianosi, C. P. Smith, A. Almudevar, and P. J. McGrath, "Dalhousie dyspnea scales: Pictorial scales to measure dyspnea during induced bronchoconstriction.," Pediatric Pulmonology, vol. 41, no. 12, pp. 1182-1187, Dec. 2006.

[19] S. C. Ratzan and R. M. Parker, "Introduction," in National Library of Medicine Current Bibliographies in Medicine: Health Literacy, C. R. Selden, M. Zorn, S. C. Ratzan, and R. M. Parker, Eds. Bethesda, MD: National Institutes of Health, 2000.

[20] B. Renner, "Biased reasoning: adaptive responses to health risk feedback.," Personality and Social Psychology Bulletin, vol. 30, no. 3, pp. 384-396, Mar. 2004.

[21] S. L. Sheridan, D. J. Halpern, A. J. Viera, N. D. Berkman, K. E. Donahue, and K. Crotty, "Interventions for individuals with low health literacy: a systematic review.," Journal of Health Communication, vol. 16 Suppl 3, pp. 30-54, 2011.

[22] C. G. Spinillo, "Graphic and cultural aspects of pictograms: an information ergonomics viewpoint," Work, vol. 41, no. Supplement 1 , pp. 3398-3403, 2012 .

[23] U.S. Department of Health and Human Services, "America's health literacy: Why we need accessible health information," 2008 Available: https://health.gov/communication/literacy/issuebrief/.

[24] J. Weiner, A. Aguirre, K. Ravenell, K. Kovath, L. McDevit, J. Murphy, D. A. Asch, and J. A. Shea, "Designing an illustrated patient satisfaction instrument for low-literacy populations," The American Journal of Managed Care, vol. 10, no. 11, pp. 853-860, 2004.

[25] B. D. Weiss, M. Z. Mays, W. Martz, K. M. Castro, D. A. DeWalt, M. P. Pignone, J. Mockbee, and F. A. Hale, "Quick assessment of literacy in primary care: The Newest Vital Sign.," Annals of Family Medicine, vol. 3, no. 6, pp. 514-522, Dec. 2005.

[26] H. S. Yin, R. M. Parker, L. M. Sanders, A. Mendelsohn, B. P. Dreyer, S. C. Bailey, D. A. Patel, J. J. Jimenez, K.-Y. A. Kim, K. Jacobson, M. C. J. Smith, L. Hedlund, N. Meyers, T. McFadden, and M. S. Wolf, "Pictograms, units and dosing tools, and parent medication errors: A randomized study.," Pediatrics, vol. 140, no. 1, Jul. 2017. 